\title{
Current status on the biodegradability of acrylic polymers: microorganisms, enzymes and metabolic pathways involved
}

\author{
Itzel Gaytán ${ }^{1}$ (i) $\cdot$ Manuel Burelo $^{2}$ (i) $\cdot$ Herminia Loza-Tavera ${ }^{1}$ (i)
}

Received: 11 July 2020 / Revised: 14 December 2020 / Accepted: 23 December 2020 / Published online: 11 January 2021

(C) The Author(s), under exclusive licence to Springer-Verlag GmbH, DE part of Springer Nature 2021

\begin{abstract}
Acrylic polymers (AP) are a diverse group of materials with broad applications, frequent use, and increasing demand. Some of the most used AP are polyacrylamide, polyacrylic acid, polymethyl methacrylates, and polyacrylonitrile. Although no information for the production of all AP types is published, data for the most used AP is around 9 MT/year, which gives an idea of the amount of waste that can be generated after products' lifecycles. After its lifecycle ends, the fate of an AP product will depend on its chemical structure, the environmental setting where it was used, and the regulations for plastic waste management existing in the different countries. Even though recycling is the best fate for plastic polymer wastes, few AP can be recycled, and most of them end up in landfills. Because of the pollution crisis the planet is immersed, setting regulations and developing technological strategies for plastic waste management are urgent. In this regard, biotechnological approaches, where microbial activity is involved, could be attractive eco-friendly strategies. This mini-review describes the broad AP diversity, their properties and uses, and the factors affecting their biodegradability, underlining the importance of standardizing biodegradation quantification techniques. We also describe the enzymes and metabolic pathways that microorganisms display to attack AP chemical structure and predict some biochemical reactions that could account for quaternary carbon-containing AP biodegradation. Finally, we analyze strategies to increase AP biodegradability and stress the need for more studies on AP biodegradation and developing stricter legislation for AP use and waste control.
\end{abstract}

\section{Key points}

- Acrylic polymers (AP) are a diverse and extensively used group of compounds.

- The environmental fates and health effects of AP waste are not completely known.

- Microorganisms and enzymes involved in AP degradation have been identified.

- More biodegradation studies are needed to develop AP biotechnological treatments.

Keywords Acrylic polymers $\cdot$ Environmental fates $\cdot \mathrm{C}$-C backbone recalcitrance $\cdot$ Biodegradation rates $\cdot$ Biodegradative pathways

Herminia Loza-Tavera

hlozat@unam.mx

1 Departamento de Bioquímica, Facultad de Química, Universidad Nacional Autónoma de México, Ave. Universidad 3000. Col. UNAM., 04510 Mexico City, México

2 Laboratorio de Química Sostenible, Departamento de Química Analítica, Facultad de Química, Universidad Nacional Autónoma de México, Ave. Universidad 3000. Col. UNAM., 04510 Mexico City, México

\section{Introduction}

Acrylic polymers (AP) are a diverse group of synthetic materials based on acrylate monomers, esters with vinyl groups attached to a carbonyl carbon (Fig. 1). The first AP were prepared in 1880 from methyl acrylate and methacrylic acid (Mosley 2017), although the industrial production began in 1927. Since then, the synthesis of new monomers and the possibility to combine them by polymerization have created a large number of different polymers with broad properties varying from good mechanical performance, transparency, elasticity, flocculation or dispersion to superabsorbent capacity, biocompatibility, and even electric qualities (Cameron et al. 2000; Mosley 2017). Progress in polymer chemistry 
has led to the production of a large spectrum of AP products with a widespread use ranging from agriculture across different industries, including food packaging, cosmetic, textile, electronic, automotive, oil, and even medical and pharmaceutical industries (Table 1). Because of their extensive use, large amounts of AP are manufactured, with growing demands predicted for the following years (Esmizadeh et al. 2019) (Table 2). Therefore, vast amounts of wastes, resulting after AP products' lifecycles end or even during their synthesis, are being generated. The different environmental fates an AP product could reach after its useful life will depend on its application, the environmental settings where the polymer was used, and the governments' norms for waste disposal. Ideally, all the AP must be recycled to produce new AP materials. However, for different reasons, this ideal situation is not reached for most of the AP types. In many cases, burning for energy waste, landfill disposition, or release in wastewaters and soil are AP ultimate fates (Table 2). Thus, some AP wastes can be contained. Others, whose application implies their release to the environment, such as soil amendments, additives in detergents, acrylic fibers, and AP used in the oil industry, cannot. For instance, 700,000 microplastic fibers are discharged in one wash load of polyester clothes (including acrylic and nylon); thus, half an MT of these clothes' fibers end up into the oceans every year, which will damage the life in ocean ecosystems and can become part of the human food chain (Šajn 2019). In any case, deliberate or unintentional releases have led to AP accumulation in the environment, promoting landfills' overflows, greenhouse gas emissions, and pollution of water bodies and soils, posing serious ecological threats (Dell'Ambrogio et al. 2019; Šajn 2019).

Table 1 Acrylic polymer types and applications

\begin{tabular}{|c|c|c|}
\hline Acrylic polymer & Abbreviation & Applications \\
\hline Polyacrylic acid & PAA & $\begin{array}{l}\text { Hand sanitizing gels, super absorbent polymers (SAP) used in diapers, surgical pads, } \\
\text { incontinence, feminine napkins, soil enhancers and hydrogel thickeners, paints, syn- } \\
\text { thetic rubbers, leather sealants, detergent builders, dispersants and flocculants in wate } \\
\text { treatments, drilling muds for crude oil recovery }\end{array}$ \\
\hline Polysodium acrylate & $\mathrm{PNaA}$ & $\begin{array}{l}\text { SAP, growing toys, dispersants in paper manufacturing, clearing of potable and industria } \\
\text { water, drilling muds for crude oil recovery }\end{array}$ \\
\hline Polypotassium acrylate & PKA & SAP, coatings, adhesives, detergents \\
\hline Polyacrylamide & PAAm & $\begin{array}{l}\text { SAP, food-contact papers, dyes, paints, varnishes, gels, adhesives, tapes, toiletries, } \\
\text { cosmetics, textile processing, clearing of potable and industrial water, drilling muds for } \\
\text { crude oil recovery }\end{array}$ \\
\hline \multicolumn{3}{|l|}{ Poly(n-alkyl acrylates) } \\
\hline Polymethyl acrylate & PMA & Coatings and paints \\
\hline Polybutyl acrylate & PBA & $\begin{array}{l}\text { Kitchen countertops, dental materials, electronic screens, adhesives, coatings, paints, } \\
\text { plastic wraps, and aircraft windows }\end{array}$ \\
\hline Polyhydroxyethyl acrylate & PHEA & Hydrogels, drug delivery systems, coatings, contact lenses and culture flasks \\
\hline Polyhydroxybutyl acrylate & PHBA & Fibers, adsorbents, surface modifiers of polyurethane tubing for biomedical applications \\
\hline \multicolumn{3}{|l|}{ Poly(n-alkyl methacrylates) } \\
\hline Polymethyl methacrylate & PMMA & $\begin{array}{l}\text { Hydrophobic coatings and paints, adhesives, tissue scaffolds, dental materials, bone } \\
\text { cements, corneal prostheses, acrylic sheets, glasses for lenses, electronic screens, and } \\
\text { aircraft windows }\end{array}$ \\
\hline Polyethyl methacrylate & PEMA & Dental materials, corneal prostheses, bone cements, and contact lenses \\
\hline Polyhydroxyethyl methacrylate & PHEMA & Hydrogels, contact lenses, cell-culture flasks coatings \\
\hline \multicolumn{3}{|l|}{ Acrylic polymers with cyano groups } \\
\hline Polyacrylonitrile & PAN & $\begin{array}{l}\text { Fibers for clothing, packaging materials, food containers, kitchenware, toys, musical } \\
\text { instruments, automotive trim components, material used in 3D printers, safety helmet }\end{array}$ \\
\hline Polycyanoacrylate & PCA & Superglue, foams, fibers and implants for bone and tissue substitution \\
\hline Styrene acrylonitrile copolymer & SAN & $\begin{array}{l}\text { Water bottles, food containers, kitchenware, packaging material, computer products, } \\
\text { battery cases, and plastic optical fibers }\end{array}$ \\
\hline Acrylonitrile styrene acrylate copolymer & ASA & $\begin{array}{l}\text { Filaments for 3D printers, mirrors, radiator grillers, electrical panels, furniture, sporting } \\
\text { goods, headlights, instrument panel in vehicles }\end{array}$ \\
\hline Acrylonitrile butadiene styrene copolymer & ABS & $\begin{array}{l}\text { Toys, musical instruments, protective headgear, 3D printers filaments, automotive trim } \\
\text { components, automotive bumper bars, colorants for tattoo inks, inhalers, nebulizers, } \\
\text { tendon prostheses }\end{array}$ \\
\hline
\end{tabular}


Table 2 Global production, environmental fates, and recycling methods of some acrylic polymers

\begin{tabular}{|c|c|c|c|c|}
\hline $\begin{array}{l}\text { Acrylic } \\
\text { polymer }\end{array}$ & $\begin{array}{l}\text { Global } \\
\text { production } \\
\text { (MT/year) }\end{array}$ & Environmental fate of AP wastes & $\begin{array}{l}{ }^{1} \text { Experimental and } * \text { industrial recycling } \\
\text { methods }\end{array}$ & Reference \\
\hline PAA & $2.0 / 2013$ & $\begin{array}{l}\text { Landfills, wastewaters, sediments, soil humid } \\
\text { fractions, surface waters, recycling }\end{array}$ & $\begin{array}{l}\text { Oxidative, photooxidative, and thermal } \\
\text { degradation, UV radiation, pyrolysis, } \\
\text { *mechanical (FaterSMART technology) }\end{array}$ & $\begin{array}{l}\text { Shukla et al. 2009; Nuss } \\
\text { and Gardner 2013; } \\
\text { Oksińska et al. 2019; } \\
\text { Dell'Ambrogio et al. } \\
\text { 2019; Fater } 2020\end{array}$ \\
\hline PAAm & $1.77 / 2018$ & $\begin{array}{l}\text { Landfills, wastewaters, sediments, soils, } \\
\text { surface waters, groundwaters, recycling }\end{array}$ & $\begin{array}{l}\text { Photolytic, oxidative, thermal, and } \\
\text { free-radical degradation, Fenton reaction, } \\
\text { hydrolysis, membrane processes } \\
\text { (microfiltration), *mechanical } \\
\text { (FaterSMART technology) }\end{array}$ & $\begin{array}{l}\text { Caulfield et al. 2002; } \\
\text { Wiśniewska 2018; } \\
\text { Xiong et al. 2018; Zhao } \\
\text { et al. 2019; } \\
\text { Dell'Ambrogio et al. } \\
\text { 2019; Fater 2020 }\end{array}$ \\
\hline PMMA & $3.36 / 2019$ & $\begin{array}{l}\text { Landfills, wastewaters, soils, incineration, } \\
\text { recycling }\end{array}$ & $\begin{array}{l}\text { Thermal degradation, *pyrolysis (P2L } \\
\text { technology), *dissolution/reprecipitation, } \\
\text { *mechanical, *incineration for cement raw } \\
\text { materials production, and energy recovery } \\
\text { (fuels); cracking (Shimi technology) }\end{array}$ & $\begin{array}{l}\text { Kikuchi et al. 2014; } \\
\text { Pemberton and } \\
\text { Lohmann 2014; Mosley } \\
\text { 2017; Esmizadeh et al. } \\
\text { 2019; P2L 2019; Shimi } \\
\text { 2020 }\end{array}$ \\
\hline PAN & $2.73 / 2006$ & $\begin{array}{l}\text { Landfills, wastewaters, soils, surface waters, } \\
\text { incineration, recycling }\end{array}$ & $\begin{array}{l}\text { Oxidative and thermal degradation, } \\
\text { low-energy ion beam, UV radiation, } \\
\text { pyrolysis, mechanical, material } \\
\text { separation/blending, *patented Shimi tech- } \\
\text { nology }\end{array}$ & $\begin{array}{l}\text { Aggour and Aziz 2000; } \\
\text { EURAR 2004; } \\
\text { Fischer-Colbrie et al. } \\
\text { 2006; Adegbola et al. } \\
\text { 2020; Shimi } 2020\end{array}$ \\
\hline
\end{tabular}

${ }^{1}$ Most recycling techniques are experimental; only the ones indicated by an asterisk are used in industrial recycling processes

Because of their polymeric nature, i.e., their high molecular weight, AP have been supposed as inert and non-toxic, with low risk of bioaccumulation in plants and animals, as they cannot pass through biological membranes (Xiong et al. 2018; Dell'Ambrogio et al. 2019); however, these must not be assumed. Little information is known about AP persistence and accumulation in the environment, and although several environmental risk assessments have been published recently (De Matos 2019; DeLeo et al. 2020), the impact of AP in ecosystems is almost unexplored, and specific regulations for their use and disposal are scarce and change from country to country (Dell'Ambrogio et al. 2019). Therefore, more studies on environmental risk assessments and international rules for controlling AP waste disposal and treatment are needed. Moreover, some AP monomers, which persist in the final products, to some extent, are considered health threats since they are toxic to human health (Xiong et al. 2018; Dell'Ambrogio et al. 2019). Acrylamide (AAm) monomers penetrate the intact skin, mucous membranes, and digestive tract, exhibiting mutagenic, teratogenic, and carcinogenic effects and inducing neuropathies (Maksimova et al. 2018), while acrylonitrile (AN) monomers are skin, respiratory, and severe eye irritants that cause dermatitis and are potent hepatotoxic, mutagenic, and carcinogenic factors (Abo-Salem et al. 2011). Also, methyl methacrylate monomers are eye, skin, and respiratory tract irritants and promote degenerative and necrotic lesions in the liver, kidney, and brain and atrophic changes in spleen and bone marrow in rats (Borak et al. 2011). Even though some microorganisms can degrade AAm monomers, biodegradation is not efficient, especially at high concentrations (Bedade and Singhal 2018).

Although recycling is the best alternative to avoid AP waste accumulation, most AP recycling methods are still experimental (Table 2). Only a few types of AP such as polymethyl methacrylate (PMMA), polyacrylonitrile (PAN), and polyacrylic acid (PAA) and PAAm used in diapers, hygienic pads, and incontinence products as superabsorbent polymers (SAP) can be processed and used as raw materials for the synthesis of new products. Unfortunately, recycling methods have been implemented in some EU countries, but in most others, AP waste treatment and disposition are not regulated; thus, landfilling and environmental release are the primary AP fates (Table 2) (P2L 2019; Fater 2020; PMMA 2018; Shimi 2020). Therefore, because of the severe environmental deterioration the planet has reached, generated by different types of pollutants, including the excessive use of plastic polymers, regulations for the utilization, reduction, contention, treatment, and recycling of different types of plastic materials, including AP products, are crucial to avoid larger problems to the environment and human societies.

In this regard, the development of biotechnological approaches for treating AP wastes would be of great help. 
Biotechnological approaches would benefit from utilizing AP biodegrading microorganisms that have evolved the capacity to attack them. AP biodegradation has been experimentally tested in bioreactors and activated sludges, with promising results depending on the AP type and microorganisms tested. Assisted bioremediation, a hybrid methodology that combines physical and chemical treatments with biological processes, has been explored for improving AP mineralization ( $\mathrm{Lu}$ and Wei 2011; Yongrui et al. 2015). Numerous articles have analyzed different aspects of AP biodegradation for almost three decades, mainly focused on PAA and PAAm (Joshi and Abed 2017; Nyyssölä and Ahlgren 2019). Nevertheless, since AP is an extensive group of materials with wide-range applications, a broader revision, including biodegradability analyses of other AP types, is needed. In this mini-review, we describe the most relevant AP types and their uses. We analyze the factors that influence AP biodegradation and its quantification (biodegradability), which depends not only on the AP type or the microorganisms involved but also on the technique used for its measurement. We examine the enzymes involved in AP biodegradation, displayed by bacteria and fungi, and the biochemical pathways proposed for the $\mathrm{C}-\mathrm{C}$ backbone cleavage, the most recalcitrant structure in the AP molecule. Besides, we suggest some reactions that could be involved in the biodegradation of poly( $n$-alkyl methacrylates), an AP that contains quaternary carbons that make the microbial attack a biochemical challenge. We conclude this revision by emphasizing that studies on AP biodegradation are needed for improving the understanding of AP impacts on ecosystems and for developing and improving biotechnological approaches for AP waste treatment. Moreover, legislation to control the use and the treatment of AP wastes are urgently needed.

\section{Acrylic polymers' chemistry, properties, and applications}

AP are produced via free-radical polymerization of acrylic monomers containing a vinyl group with a $\mathrm{C}-\mathrm{C}$ double bond that acts as an active center that propagates to produce polymer chains (Fig. 1). Depending on the monomers used in polymerization, AP may have diverse qualities, useful for different applications. PAA is synthesized from acrylic acid (AA) monomers. PAA and its salts, polysodium acrylate, and polypotassium acrylate (Fig. 2a) are used to synthesize different products, such as additives in detergents and hand sanitizing gels and for manufacturing SAP. SAP are hydrophilic gels with molecular weight $(\mathrm{Mw})$ ranging from $10^{3}$ to $10^{6} \mathrm{Da}$, which can absorb 500- to 1000 -fold the amount of water relative to their mass (Zohuriaan-Mehr and Kabiri 2008). SAP are widely used as soil enhancers, in diapers and feminine napkins (Table 1). PAAm (Fig. 2a) is a high $\mathrm{Mw}$ polymer $\left(10^{3}\right.$ to $\left.10^{7} \mathrm{Da}\right)$, synthesized from AAm monomers,

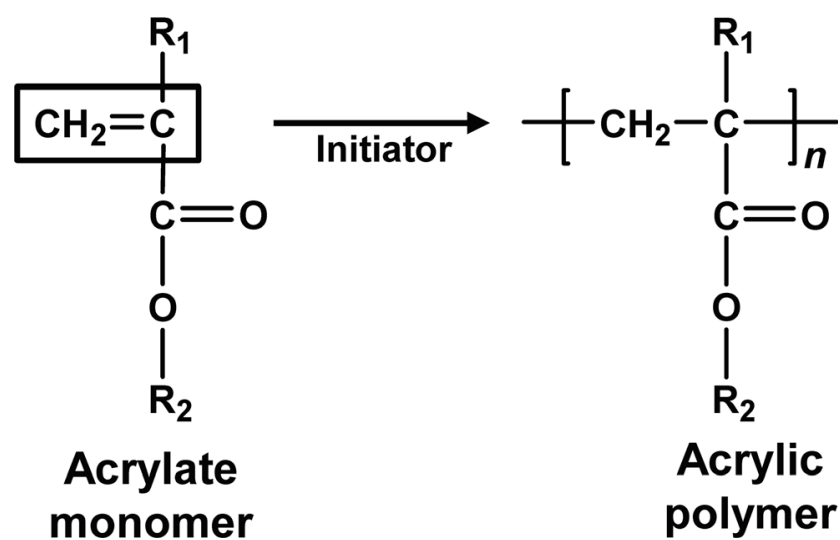

Fig. 1 Acrylic polymer synthesis. Acrylate monomers containing a vinyl group (box) are polymerized in a free-radical reaction. At initiation, an active center is developed in the double bond, and radicals are produced; then, monomers' addition generates chain's propagation; finally, termination occurs by the radicals' disproportion

using thermal initiators and redox systems. It has multiple applications as homopolymer or copolymer with PAA for SAP production, used as a soil conditioner in agriculture, enhancer of solid/liquid separation in mineral extraction, and other applications (Xiong et al. 2018; Nyyssölä and Ahlgren 2019) (Table 1).

Poly(n-alkyl acrylates) (PnAA), such as polymethyl (PMA), polyethyl (PEA), polybutyl (PBA), polyhydroxyethyl, and polyhydroxybutyl acrylates, are derived from acrylate monomers having an $n$-alkyl side group (Fig. 2a). This structure confers them peculiar crystallization and thermal and gas permeability properties, making them ideal for the fabrication of complex plastics with specialized purposes in biomedical, agricultural, and electronic industries (Mahalik and Madras 2005; O'Leary and Paul 2006; Morro et al. 2016; Serrano-Aroca 2017) (Table 1).

Poly (n-alkyl methacrylates) (PnAMA) are synthesized from acrylic monomers with a methyl substituent in the $\alpha-\mathrm{C}$ and an alkyl, or hydroxyl alkyl, bound by an ester, forming quaternary carbons in their main chain after polymerization. The most used are PMMA, polyethyl methacrylate, and polyhydroxyethyl methacrylate (Fig. 2b). They are very resistant and versatile, with high environmental stability; PMMA, for example, is the material of choice for outdoor applications, used as a glass substitute (casting or extruded acrylic sheets). In the context of the Covid-19 pandemic, a new application for acrylic sheets as protective barriers has emerged across the globe to prevent coronavirus from spreading. Also, PMMA resins are molded for lens production because of their biocompatibility and optical properties (Table 1).

PAN and polycyanoacrylate (PCA) are AP containing cyano substituent bound to the $\alpha$-C in their structure (Fig. $2 \mathrm{a}$ and b). PCA also contains a methyl group bound by an ester bond to the $\alpha$-C. PAN is widely used to produce textile fibers (acrylic) (Serrano-Aroca 2017) and PCA is used as a structural 

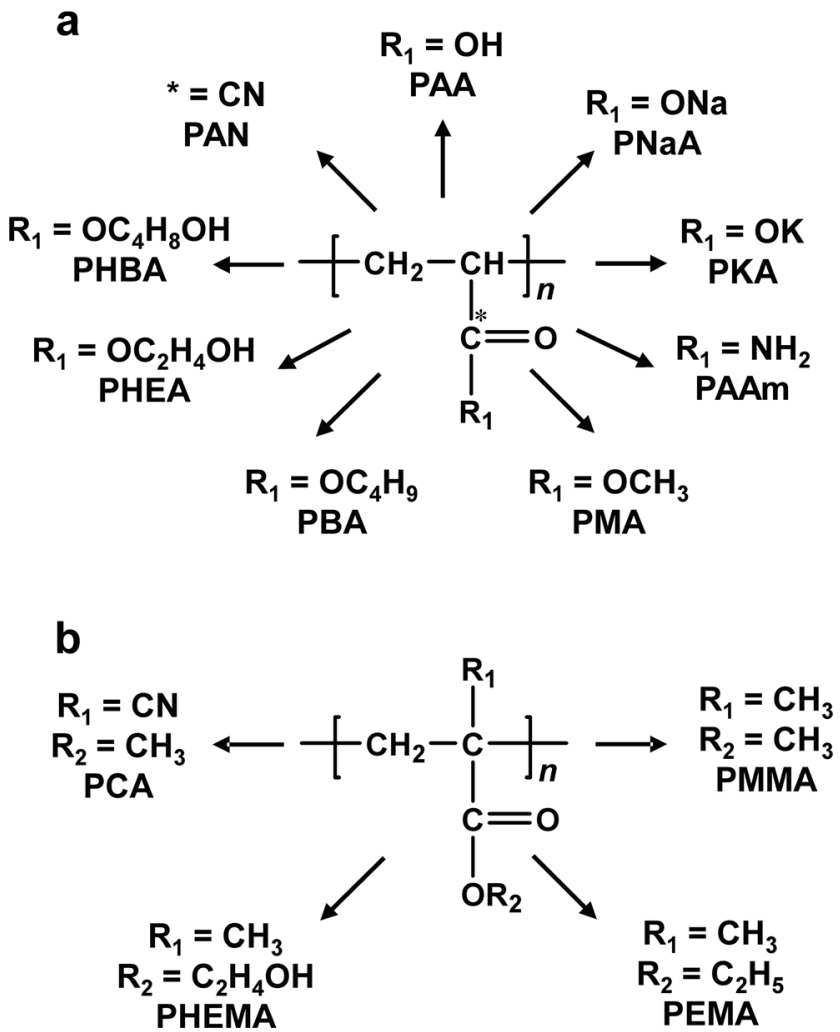

Fig. 2 Chemical structures of some acrylic polymers (AP). (a) AP derived from acrylate monomers have different functional groups bound to the carbonyl $\left(\mathrm{R}_{1}\right)$ : PAA, polyacrylic acid; $\mathrm{PNaA}$, polysodium acrylate; PKA, polypotassium acrylate; PAAm, polyacrylamide. Poly $(n-$ alkyl acrylates) (PnAA) are polymers derived from acrylate monomers with an $n$-alkyl side group: PMA, polymethyl acrylate; PBA, polybutyl acrylate; PHEA, polyhydroxyethyl acrylate; PHBA, polyhydroxybutyl acrylate. PAN, polyacrylonitrile, has a cyano group substituent bound to the $\alpha$-C. (b) Poly ( $n$-alkyl methacrylates) (PnAMA), are synthesized from acrylate monomers with a methyl group attached to the $\alpha-C\left(R_{1}\right)$, and different functional groups bound by an ester $\left(\mathrm{R}_{2}\right)$ : PMMA, polymethyl methacrylate; PEMA, polyethyl methacrylate; PHEMA, polyhydroxyethyl methacrylate. PCA, polycyanoacrylate, has a cyano substituent bound to the $\alpha-\mathrm{C}$ and a methyl bound by an ester

adhesive for plastics, rubbers, and ceramics and can be applied as surgical adhesive (Rustamov et al. 2014). Cyano substituent is also included in some styrene copolymers such as styrene-acrylonitrile (SAN), acrylonitrile styrene acrylate (ASA), and acrylonitrile butadiene styrene (ABS), a widely used group of thermoplastics to produce light, rigid, molded materials for toys, safety helmets, electronics, automobile bumps, and building construction (McKeen 2012) (Table 1).

\section{Factors affecting acrylic polymers' biodegradability}

During AP biodegradation, physical, chemical, and biological processes occur, which are also influenced by environmental factors such as temperature, UV radiation, $\mathrm{pH}$, and humidity.
AP biodegradation involves enzyme-catalyzed reactions that transform the polymer chemical and physical properties. During the initial transformation, usually described as primary biodegradation, low $\mathrm{Mw}$ components from the polymeric structure are released and transported into microbial cells. Once inside the cells, ultimate biodegradation or mineralization occurs, using these components as energy and $\mathrm{C}$ source for biomass formation, resulting in fully reduced or oxidized products $\left(\mathrm{CO}_{2}, \mathrm{H}_{2} \mathrm{O}\right)$ (Kolvenbach et al. 2014). In the assessment of AP biodegradability, the essential aspects that should be considered are: the polymer structure, the microbial AP attacking capacity sustained by proper culture or environmental conditions, and the techniques used for biodegradation quantitation. Altogether, these aspects will define the time an AP will last for being degraded, that is, its biodegradation rate. The main aspects of AP structure that affect biodegradation include the $\mathrm{C}-\mathrm{C}$ backbone length, the side groups, quaternary carbons, and molecular organization (linear, branched, or cross-linked). Other characteristics such as purity of the product and degree of hydrolysis also influence AP biodegradability assessment (Seybold 1994; Larson et al. 1997; Kay-Shoemake et al. 1998a; Stahl et al. 2000).

\section{C-C backbone size and recalcitrance}

The $\mathrm{C}-\mathrm{C}$ backbone confers a very stable, thus recalcitrant molecular structure, whose cleavage is a crucial step in AP mineralization. Even that AP biodegradation rates reported in different articles are diverse, when comparing experiments where similar polymers, microbial systems, laboratory conditions, and analytical techniques were tested, they show an inverse correlation between the size of the $\mathrm{C}-\mathrm{C}$ backbone and the mineralization rate (Supplementary table S1). For instance, complete biodegradation of acrylic acid monomers and dimers (100\% $\mathrm{CO}_{2}$ production) was observed in $28-32$ days (Freeman et al. 1996; Cook et al. 1997; Larson et al. 1997), while PAA oligomers and $\mathrm{PNaA}$ (trimers to decamers) can be extensive but incompletely degraded $\left(60-80 \% \mathrm{CO}_{2}\right.$ production) in $14-32$ days ( $~ 3 \%$ per day) (Hayashi et al. 1993; Freeman et al. 1996; Larson et al. 1997). For PAA and $\mathrm{PNaA}$ of $1000 \mathrm{Da}$, biodegradation values of $30-40 \%$ measured as $\mathrm{CO}_{2}$ production in $28-32$ days $(\sim 1.16 \%$ per day) (Freeman et al. 1996; Larson et al. 1997), 7.4\% measured as BOD/ThOD in 10 days ( $0.74 \%$ per day) (Kawai 1993), and $73 \%$ measured as total organic carbon (TOC) in 14 days (5.21\% per day) (Hayashi et al. 1994) have been reported. For larger polymers (2000-4500 Da), biodegradation levels of 8-20\% measured as $\mathrm{CO}_{2}$ production in $28-32$ days $(\sim 0.5 \%$ per day) (Freeman and Bender 1993; Freeman et al. 1996; Larson et al. 1997), 2-3.9\% measured as BOD/ThOD in 10 days ( $\sim 0.3 \%$ per day) (Kawai 1993$)$, and $20 \%$ measured as TOC in 14 days (1.4\% per day) (Hayashi et al. 1994) have been determined. Therefore, the size of the $\mathrm{C}-\mathrm{C}$ backbone is a critical factor in AP biodegradation. Interesting results were 
observed when analyzing long-time biodegradation experiments in soil, with labeled PAA to quantify the $\mathrm{C}$-C backbone cleavage. In microcosm experiments containing soil microorganisms, mineralization rates of $3.6 \%$ in 90 days $(0.04$ per day) or $6 \%$ in 42 days ( 0.14 per day) were observed for ${ }^{14} \mathrm{C}$ labeled PAA, previously solubilized in cultures of Phanerochaete chrysosporium induced to produce peroxidases or cellobiose dehydrogenase $(\mathrm{CDH})$, respectively (Stahl et al. 2000). In similar experiments, a ${ }^{13} \mathrm{C}$-labeled PAA of unknown size was mineralized by soil microorganisms in four common agricultural soils, $0.12-0.24 \%$ in 6 months $(\sim$ $0.001 \%$ per day) (Wilske et al. 2014) (Supplementary table $\mathrm{S} 1)$. These results show differences in biodegradation rates between experiments performed in culture media during short times compared to experiments performed in soil during more prolonged periods. These results may have been obtained because short-term analysis measures the more straightforward degradation reactions, but in the more extended experiments, the more complex, late biodegradative reactions are also measured. These also exhibit that the biodegradation rate is not a linear process, which should be considered when planning experiments for measuring this parameter.

\section{Side groups}

The existence of side groups in AP chemical structure must be taken into account in biodegradation assessment. Since they are the first groups cleaved during biodegradation, a quantification analysis based only on the side groups' release will overestimate the polymer biodegradation rate. For instance, removal efficiencies of $70-76 \%$ in 5 days $(\sim 14.6 \%$ per day) for PAAm $(16,000 \mathrm{kDa})$ were reported when the starchcadmium-iodine (SCI) method that quantifies the release of amides was used for the analysis (Wen et al. 2010). On the other hand, when ${ }^{14} \mathrm{C}$-labeled PAAm and more extended monitoring periods were followed, slower biodegradation rates were observed. Thus, mineralization of $22.5 \%$ was quantified for a cationic ${ }^{14} \mathrm{C}$-labeled PAAm/[2-(acryloyloxy) ethyl] trimethyl ammonium chloride (AETAC) copolymer (6000 $\mathrm{kDa})$ exposed to sludge-treated soils for 2 years $(0.03 \%$ per day) (Hennecke et al. 2018). Also, a removal efficiency of $32.9 \%$ of hydrolyzed PAAm (HPAAm) $(22,000 \mathrm{kDa})$, determined by TOC analysis, was obtained after 20 days of incubation (1.6\% per day) with mixed cultures of Bacillus cereus and Rhodococcus strain EF028124, which was almost three times slower than that measured in a similar system by the SCI method, i.e., $89.8 \%$ in 20 days (4.5\% per day) (Sang et al. 2015) (Supplementary table S1). Interestingly, evidence that the presence of amide groups facilitates AP biodegradation was shown in experiments where ${ }^{14} \mathrm{C}$-labeled PAAm/PAA or PAA were exposed for 76 days to soil microcosms inoculated with $P$. chrysosporium, causing mineralization rates of $7.3 \%$ ( $0.1 \%$ per day) and $0.95 \%$ (0.01 per day), respectively
(Stahl et al. 2000) (Supplementary table S1). The influence of other side groups, such as nitriles or alkyl groups, as methyl in PnAMA, has not been analyzed in AP biodegradation. Even though the enzymatic elimination of these side groups before the biochemical attack to the AP C-C backbone has to occur, it is unknown if their presence facilitates the whole polymer's biodegradation. Therefore, studies to analyze this possibility are needed. The existence of repetitive quaternary carbons in PnAMA (Fig. 2) increases the C-C backbone's recalcitrance, strongly limiting biodegradation. PnAMA recalcitrance was evident when a sodium methacrylate oligomer was exposed, in a 14-day experiment, to Arthrobacter sp. strain NO-18, capable of degrading Na acrylate oligomers, but not the methacrylate oligomer (Hayashi et al. 1993). In a future section, we will suggest, based on what has been observed in other types of compounds with quaternary carbons, that enzymatic reactions attacking quaternary carbons in PnAMA could be possible.

\section{Residual monomers and linear polymers}

Commercial AP are not pure chemical products; they generally contain variable amounts of residual monomers or, in the case of cross-linked AP, they also have linear molecules (Bai et al. 2015; Dell'Ambrogio et al. 2019). Although these components do not contribute to the polymer's functionality, they might affect the polymer biodegradation assessment. No reports analyzing how residual monomers affect AP biodegradation have been published. However, the presence of monomers in polymer products could lead to overestimation of the biodegradation rates. On the other hand, for cross-linked PAA, the linear fraction present in the product is relevant for calculating biodegradation rates. Biodegradation measurements of two different Mw linear PAA were used to calculate their contribution to a cross-linked PAA's biodegradation rate, considering that about 4\% remains linear (Bai et al. 2015; Wilske et al. 2014). The analysis showed that short-sized linear polymers have a more considerable contribution than the long-sized linear polymers in the cross-linked polymer's biodegradation rate (Bai et al. 2015). Therefore, since impurities on AP products influence biodegradation assessment, they should be pondered during experiments to avoid overestimating polymers' biodegradability.

\section{Enzymatic activities and pathways involved in microbial AP degradation}

Several environmental microorganisms are capable of biodegrading some AP types, and they have been studied either isolated or in communities (Supplementary table S1). Identifying AP biodegrading microorganisms and elucidating 
the catabolic pathways responsible for this capacity are fundamental for understanding the biodegradative process and developing or improving biotechnological techniques for AP waste treatment. Biochemical analysis of AP biodegradation has been mainly focused on PAA or PAAm, and several enzymatic reactions and metabolic pathways have been described, based on the metabolites and the enzymatic activities detected (Joshi and Abed 2017; Nyyssölä and Ahlgren 2019). Since all AP have basic structural similarities, we propose that most AP may be biodegraded in a two-phase process.

\section{First phase: enzymatic elimination of side groups}

In this phase, the different AP side groups, i.e., amide, nitrile, or alkyl groups bound by ester bonds, are cleaved from the C$\mathrm{C}$ backbone by hydrolytic enzymatic activities, resulting in PAA or PAA-like molecules and low Mw intermediates (Fig. 3a). Enzymatic activities such as amidases, nitriledegrading enzymes, esterases, and lipases have been responsible for AP side group modifications (Tauber et al. 2000; Mahalik and Madras 2005; Fischer-Colbrie et al. 2006; Zhao et al. 2019; Gitalis et al. 2019: Huang et al. 2018).

\section{Amidases}

Amidases or amidohydrolases are ubiquitous and versatile enzymes that cleave C-N bonds (Sharma and Nand 2009). Amidases that hydrolyze amides from AAm monomers, producing ammonium and acrylic acid, have been detected in several bacterial species (Joshi and Abed 2017). Different aspects such as culture conditions for inducing maximal expression, gene regulation, protein purification, and even directed evolution have been studied in amidases degrading AAm monomers (Jebasingh et al. 2013; Joshi and Abed 2017; Silman et al. 1991). However, little is known about PAAm amidases, which are inducible extra- and intracellular enzymes produced by microorganisms isolated from PAAmtreated soils selected by enrichment in cultures with PAAm as the only N source. Since PAAm cannot get across the cell membrane, it has been suggested that PAAm amidase induction is mediated by an unknown metabolite resulting from initial degradation steps (Kay-Shoemake et al. 1998a, b). In Pseudomonas putida HI47, a 35-45 kDa PAAm-induced extracellular aliphatic amidase converted the amide groups of a high Mw PAAm (17,000-22,000 kDa) into carboxyl groups under aerobic conditions ( $\mathrm{Yu}$ et al. 2015). Also, amidase activity was demonstrated to be responsible for transforming PAAm into PAA during anaerobic biodegradation with a wastewater microbial community that includes Bacteriodetes, Firmicutes, Proteobacteria, Spirochaetes, and others (Dai et al. 2015). Also, urease activity has been correlated with HPAAm degradation in an upflow anaerobic sludge blanket reactor system, where Proteobacteria, Chloroflexi,
Bacteriodetes, Fusobacteria, and others were identified (Zhao et al. 2019). The significant role of ureases on HPAAm biodegradation was demonstrated by enzyme inhibition experiments in aerobic cultures of Bacillus megaterium SZK-5. The total nitrogen removal rate was lower at higher urease inhibitor concentration, but the HPAAm Mw was not affected as observed with no inhibitor, suggesting that the polymer backbone's cleavage requires the previous removal of the amide group by urease. This urease activity was mainly detected in the extracellular fraction (Song et al. 2019).

\section{Nitrile-attacking enzymes}

Nitrilases hydrolyze nitriles to carboxylic acids and $\mathrm{NH}_{3}$, while nitrile hydratases catalyze nitriles conversion to amides that subsequently are hydrolyzed to carboxylic acids and $\mathrm{NH}_{3}$ by amidases (Yamada and Kobayashi 1996; Gong et al. 2012). Several bacteria produce one or both nitrile-attacking enzymes, which transform PAN into PAA (Fig. 3a) (Tauber et al. 2000; Fischer-Colbrie et al. 2006; Matamá et al. 2007). Both enzymes are produced under inducible or constitutive conditions, depending on the nutrients utilized during microbial cultivation (Yamada and Kobayashi 1996; Gong et al. 2012), being an advantage for future studies on PAN waste biodegradation. The direct conversion of PAN into PAA by the action of nitrilases was demonstrated by incubating the polymer with commercial enzymes and measuring ammonia release (Matamá et al. 2007) and analyzing the modifications in nitrilase-treated PAN by ATR-FTIR spectra (Akkaya and Ozseker 2019). The nitrile hydratase/amidase system produced by $R$. rhodochrous NCIMB 11216, induced by propionitrile, hydrolyzes PAN (granular and fibers) measured as ammonia release by spectrometry and confirmed by X-ray photoelectron spectroscopy (Tauber et al. 2000). In Agrobacterium tumefaciens BST05, the nitrile hydratase/ amidase system was induced in a medium containing acetonitrile. Here, the enzymatic reaction was analyzed on PAN-powder, and the increase in $\mathrm{O} / \mathrm{C}$ ratio $(80 \%)$ on its surface indicates the incorporation of oxygen into the polymer, which results from the hydrolysis of nitrile to amide (FischerColbrie et al. 2006). Theoretically, nitrilases and the nitrile hydratase/amidase system could similarly act on PCA, eliminating the cyano group as we propose in Fig. 3c. However, no information exists about the role of these activities on PCA biodegradation. Nitrile-attacking enzymatic reactions are of environmental interest for decontamination of soil and water (Müller and Gabriel 1999; Chand et al. 2004).

\section{Esterases}

The esterases' role in attacking AP ester bonds (Fig. 3a) was first suggested for the biodegradation of a copolymer of AAm and cationic monomers based on ester-containing compounds 
Fig. 3 Metabolic pathways for acrylic polymers (AP) biodegradation. (a) First phase (light gray rectangle): enzymatic attacks to amide, ester, and cyano side groups produce polyacrylic acid (PAA) (white square). (b) Second phase (medium gray rectangle): for the oxidation of the PAA C-C backbone, several aerobic and anaerobic metabolic pathways have been proposed. (c) Suggested pathway for polycyanoacrylate (PCA) biodegradation (dark gray rectangle). After cyano and ester group cleavage by nitrile-attacking enzymes and esterases, an acrylic acid analog is produced. This intermediate could be further oxidized. Gray arrows indicate hypothetical reactions

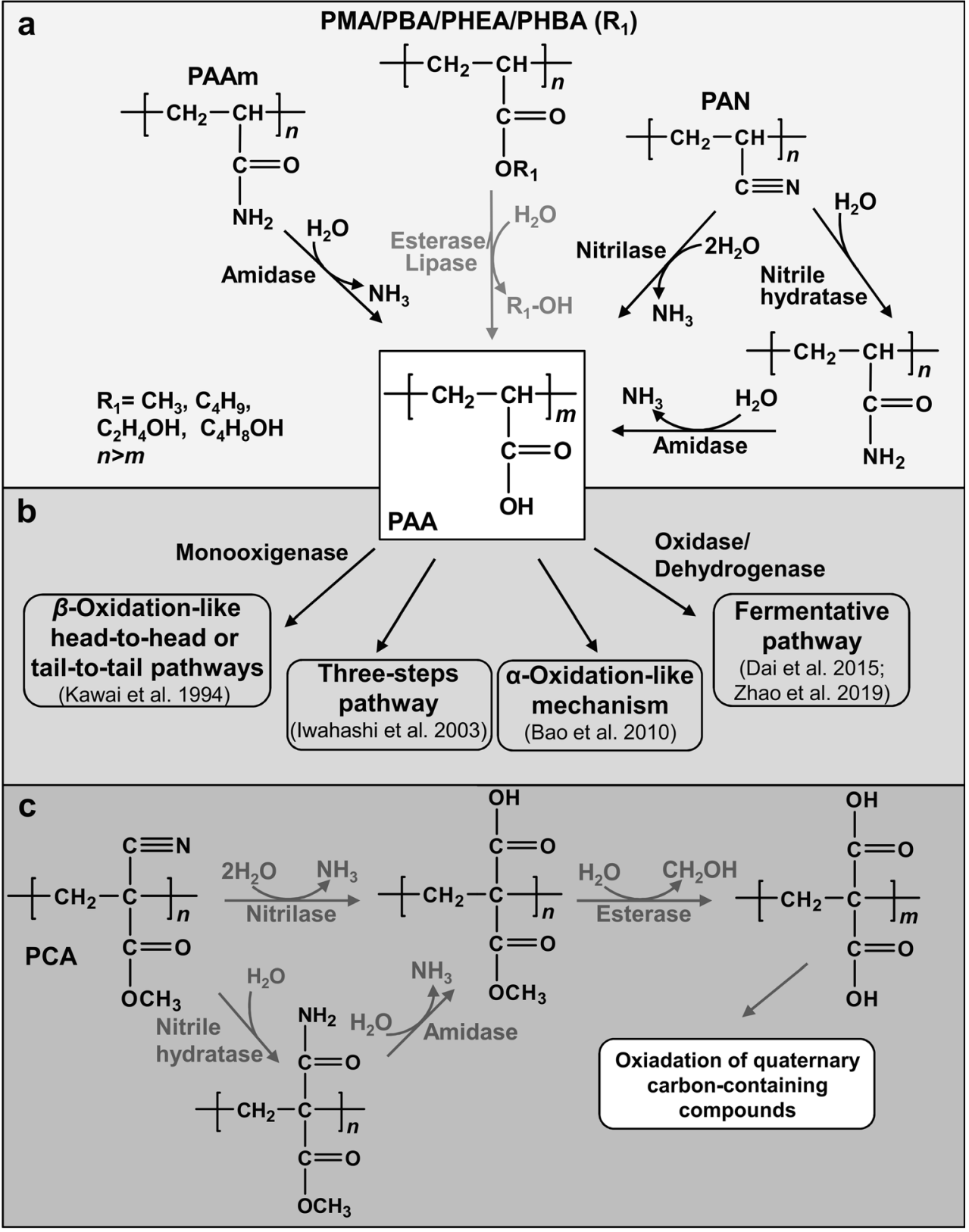

(Chang et al. 2005). In other work, esterase activity was detected when the biodegradability of fiberglass acrylic composite filters made of poly(ethylene terephthalate), polyvinyl alcohol, PMA, and PEA by two Trichoderma harzianum strains was analyzed (Sein et al. 2009). Studies on biodegradation of dental composites have shown that neutrophils in the oral cavity contain cholesterol esterase-like activities that could contribute to the degradation of methacrylate resins (Gitalis et al. 2019). Recently, studies on biodegradation of a methacrylate restoration tooth composite have shown that an esterase (SMU_118c) of Streptococcus mutans UA159, an etiological agent in dental caries, is capable of catalyzing the hydrolysis of the resinous matrix of polymerized composites and adhesives by overexpression of the esterase gene (Huang et al.
2018). Moreover, our research group found that extracellular esterase activity from microbial communities selected from a landfill was higher when grown in a commercial acrylic dispersion (Bayhydrol@) than when grown in a non-acrylic polyurethane dispersion (Neorez®), used as sole carbon sources. Besides, an increase in FTIR's carbonyl signal when the polymer was exposed to the selected microbial communities supports esterase activity participation in AP biodegradation (Vargas-Suárez et al. 2019). The role of lipases has also been studied in AP biodegradation. In vitro biodegradation of PBA, PEA, and PMA by commercial lipases such as Novozym 435, Lipolase, and an enzyme from porcine pancreas (Sigma) was investigated in different solvents (benzene, toluene, xylene, chlorobenzene) and at various temperatures. The highest 
enzymatic degradation rate (PMA > PBA $>$ PEA) was with porcine pancreas activity in toluene at $50{ }^{\circ} \mathrm{C}$ (Mahalik and Madras 2005). We suggest that esterases could also be involved in eliminating the methyl group bound by an ester bond in PCA, releasing a compound containing quaternary carbons that could be oxidized (Fig. 3c), similarly to PnAMA, as we will discuss later.

\section{Second phase: cleavage of the acrylic polymers C-C backbone}

\section{Aerobic pathways}

The AP C-C backbone cleavage requires oxidative mechanisms to act after the side groups' initial hydrolysis occurs during the first phase (Fig. 3a and b; Supplementary table S1). Several oxidative pathways have been proposed based on the degradation products and the enzymatic activities detected during AP biodegradation (Fig. 3b). The first aerobic AP biodegradative pathway was suggested based on the propionic acid metabolism carried out by cell-free extracts of Propionibacterium shermanii (Kawai 1993). Propionic acid metabolism involves the esterification of propionic acid to acrylyl CoA and its reduction to propionyl CoA (Swick 1962). An analogous mechanism in which PAA activation by acyl-CoA synthetase, a key enzyme in $\beta$-oxidation, generates PAA-CoA, was suggested (Kawai 1993). Acyl-CoA synthetase activity was measured in cell-free extracts from Microbacterium sp. II-7-12, Xanthomonas maltophilia W1, and Acinetobacter genospecies $11 \mathrm{~W} 2$ axenic cultures able to grow in 1,3,5-pentane tricarboxylic acid (PTCA), a model molecule for studying AP biodegradation (Kawai 1993). Later on, three PTCA metabolic products were identified, supporting the idea that a metabolic pathway similar to $\beta$ oxidation accounted for the PTCA metabolism. Moreover, considering the resulting AA polymerization structures, two different mechanisms for PAA biodegradation, a head-to-head and a tail-to-tail pathway, were suggested by analogy to the PTCA metabolism (Kawai et al. 1994). On the other hand, during PNaA biodegradation by the L7-98 consortium, another oxidative mechanism based on the identification of low $\mathrm{Mw}$ products was proposed. This mechanism is suggested to occur via a three-step process: (a) oxidation of the terminal methylene $(\alpha-\mathrm{C})$ to a carbonyl; (b) replacement of the terminal carboxyl by hydrogen during decarboxylation, followed by the formation of a double bond between the $\alpha-\mathrm{C}$ and $\beta-\mathrm{C}$ by dehydrogenation; and (c) oxidation of the terminal aldehyde to a carboxyl, and oxygenation of one of the carbons in the double bond, followed by dehydrogenation and release of acetic acid. The remaining molecule is shortened by repeating steps 2 and 3 (Iwahashi et al. 2003). Years later, a novel metabolic pathway for HPAAm biodegradation by two Bacillus species was proposed (Bao et al. 2010). This pathway integrates side groups' deamination to produce PAA and C-C backbone metabolism by a fatty acids $\alpha$-oxidation-like mechanism based on monooxygenase activities. Initially, the $\alpha-\mathrm{C}$ is oxidized to alcohol, transformed into carbonyl, and later to carboxyl, resulting in the main chain's cleavage and low Mw compounds (Bao et al. 2010). In this work, experimental evidence for deamination was presented, but no evidence for the $\mathrm{C}-\mathrm{C}$ backbone cleavage or the enzymatic activities were offered. Recently, the role of Cytochrome P450 (CytP450) on PAAm biodegradation by B. megaterium SZK-5 was demonstrated by enzyme activity inhibition experiments. High concentrations of the inhibitor resulted in a significant decrease of TOC removal rate and the non-reduction of polymer $\mathrm{Mw}$, suggesting that CytP450 participates in the C-C backbone cleavage and carbon biotransformation. Analysis of TOC removal rate by extracellular, periplasmic, and cytoplasmic fractions revealed that the CytP450 activity is located in the cytoplasm and extracellular or a membrane-bound urease activity is previously required for the oxidation of the $\mathrm{C}-\mathrm{C}$ backbone (Song et al. 2019). Recent studies in our group revealed the catalytic capability of a landfill microbial community selected to aerobically degrade a polyether-polyurethane-acrylate copolymer from a commercial coating (PolyLack $®$ ). By FTIR spectroscopy, changes in signal intensity showed the catabolism of the acrylate component. Besides, by a proximity ligation-based-metagenomic analysis, genes encoding oxidative enzymes for alkane metabolism such as alkane 1monooxygenases, unspecific monooxygenases, long-chain alkane monooxygenases, or reductive enzymes such as alcohol dehydrogenases (ADH) and aldehyde dehydrogenases (ALDH), as well as a large number of genes encoding acetyl-CoA C-acetyltransferases (20 genes) and acyl-CoA synthetases (10 genes), involved in $\beta$-oxidation, were revealed. Besides, genes encoding esterases and amidases were also identified. The identification of these genes suggests that some of the encoded proteins could be involved in AP biodegradation. Esterases and amidases would attack AP side groups, monooxygenases would activate the aliphatic acrylate chains (C-C backbone) by terminal or subterminal oxidations, and ADH and ALDH would generate intermediate compounds that can be channeled to $\alpha$ or $\beta$-oxidation (Gaytán et al. 2020).

\section{Anaerobic pathways}

Anaerobic pathways for AP biodegradation have been proposed after demonstrating the biological degradation of PAAm in waste-activated sludges (Dai et al. 2014) and assaying enzymatic activities proposed to participate in PAAm biodegradation (Dai et al. 2015). After amidases convert PAAm to PAA (first phase), PAA's transformation to acetyl-CoA and pyruvic acid occurs. Subsequently, these intermediates were transformed into acetic, butyric, propionic, 
or fumaric acids. Increments in amidase, ADH, phosphotransacetylase, acetate kinase, phosphotransbutyrylase, butyrate kinase, oxaloacetate transcarboxylase, and CoA transferase activities were observed in experiments with larger PAAm degradation (Dai et al. 2015). Similar results were observed for HPAAm fermentation by an activated sludge microbial community integrated by Proteobacteria, Bacteriodetes, and Chloroflexi, among others, in which dehydrogenase and urease activities correlated with HPAAm biodegradation. The hydrolysis of C$\mathrm{N}$ by ureases, followed by the participation of dehydrogenases and monooxygenases (non-demonstrated), producing acetyl-CoA, pyruvic acid, and organic acids (acetic, propionic, and butyric) as biodegradation products, was proposed (Zhao et al. 2019).

\section{Fungal enzymes}

The extracellular lignin-degrading system from the fungus $P$. chrysosporium, which involves lignin peroxidases, manganese peroxidases $(\mathrm{MnP})$, versatile peroxidases, and laccases, as well as the extracellular reductases and $\mathrm{CDH}$, has been shown to cleave the AP C-C backbone (Sutherland et al. 1997; Stahl et al. 2000). Culture conditions for the selective expression of these fungal enzymes, based on nitrogen limitation or sufficiency and different carbon sources, have been defined. When the lignin-degrading system is induced, ${ }^{14} \mathrm{C}$ labeled cross-linked high Mw PAA and PAA/PAAm were completely depolymerized to water-soluble metabolites in 15-18 days, but only $8 \%$ mineralization was reached. In longer incubation times (> 18 days), more than $80 \%$ of the radioactivity was detected in fungal mycelia, suggesting that the AP carbon was metabolized and assimilated (Sutherland et al. 1997). The selective participation of enzymes from the lignin-degrading system and their role in the biodegradation of PAA and a PAA/PAAm copolymer was demonstrated in a cooperative process between $P$. chrysosporium and soil microorganisms. This synergistic process was observed in microcosms composed of sawdust inoculated with the fungus and non-sterilized soil for 76 days. Mineralization levels in microcosms containing both biological systems were larger (PAA: $0.95 \%$, PAA/PAAm: $7.3 \%$ of ${ }^{14} \mathrm{CO}_{2}$ ) than those in which only soil microorganisms (PAA: $0.22 \%$, PAA/ PAAm: $0.35 \%$ of ${ }^{14} \mathrm{CO}_{2}$ ) or only fungus (PAA: $0.76 \%$, PAA/PAAm: $4.3 \%$ of ${ }^{14} \mathrm{CO}_{2}$ ) were present (Supplementary table S1). Moreover, the polymers incubated with the fungus grown at specific conditions for peroxidases or $\mathrm{CDH}$ induction were solubilized. When the fungus-treated polymers were added to a soil microcosm, the mineralization process improved up to 27 times compared to the polymer only treated by the soil microcosm (Stahl et al. 2000) (Supplementary table $\mathrm{S} 1)$. In other work, at induction conditions for P. chrysosporium $\mathrm{CDH}$ activity, insoluble cross-linked PAA and a PAA/PAAm copolymer were solubilized and mineralized. Moreover, the addition of iron improved the biodegradation process (Cameron et al. 2000).

\section{The biochemical challenge of poly( $n$-alkyl methacrylates) biodegradation: a hypothesis}

In PnAMA, the presence of repetitive quaternary carbons in their main chain and the different isomeric structures generated by random polymerization (Fig. 4) make biodegradation a challenging task. Quaternary carbons confer PnAMA high recalcitrance since the oxidative reactions needed for channeling the $\mathrm{C}$ - $\mathrm{C}$ backbone into $\beta$-oxidation are blocked because of the steric hindrance of methyl groups (Chiellini et al. 2003). The few works addressing PnAMA biodegradability by bacteria or fungi are coincident that these materials are highly recalcitrant (Hayashi et al. 1993; Sabatini et al. 2018). However, based on what has been observed in biodegradation studies of other compounds containing quaternary carbons, such as pivalic acid and isooctane (Probian et al. 2003; Solano-Serena et al. 2004), PnAMA biodegradation might be feasible. In the biodegradation mechanisms proposed for these compounds, the activity of mutases and decarboxylases has been suggested, based on the identified biodegradation products. These activities would transform quaternary carbons into tertiary carbon compounds, allowing that other subsequent biochemical reactions may act over them (Probian et al. 2003; Solano-Serena et al. 2004). For PnAMA biodegradation, the esterase hydrolytic attack to cleave the side groups must be the first step. This activity on PnAMA has been observed in neutrophils and S. mutans UA159 (Gitalis et al. 2019; Huang et al. 2018). After that, a PAA-like compound with methyl substituents attached to some carbons will be produced. In this compound, the terminal carbon, tertiary or quaternary, will define the biodegradative mechanism's initial step (Fig. 4). In any case, the carboxyl of the terminal unit has to be activated by acyl-CoA transferase. Therefore, polymers with terminal tertiary carbon such as head-to-head and tandem isomers can undergo a $\beta$-oxidation cycle (Fig. 4). However, isomers with a terminal quaternary carbon (tail-totail) would require mutase activity to integrate the methyl substituent attached to the $\alpha-\mathrm{C}$ into the $\mathrm{C}-\mathrm{C}$ main chain, which channels it into $\beta$-oxidation until a new quaternary carbon would be found. After a first $\beta$-oxidation cycle, mutases or decarboxylases would be required to process the polymer's quaternary carbons. Each $\beta$-oxidation cycle will shorten the polymer in three or two carbons, producing propionyl $\mathrm{CoA}$ as the main product and acetyl-CoA from one of the isomers. By the action of phosphate transferases and kinases, these compounds will be transformed into organic acids as proposed for branched-chain fatty acid metabolism (Narihiro et al. 2016) (Fig. 4). No microorganisms capable of degrading PnAMA 
have been reported so far; this might be because the proper conditions for growing microorganisms with this capacity have not been discovered. Besides, some microorganisms might require longer cultivation periods for displaying a unique capacity.

\section{Strategies to increase AP biodegradability: structure modifications and hybrid degradation methods}

AP containing components inducing higher polymer biodegradability have been synthesized as an approach to overcome the limitations imposed by the C-C backbone recalcitrance, and some of them have provided positive results
(Supplementary table S1). This strategy's rationale is to polymerize in the C-C backbone or add, as side groups, some compounds that favor cleavage, decreasing AP size. Radicals generating phenolic compounds such as $p$ - and $o$ aminophenol, and non-phenolics such as $p$-aminoaniline and acrolein, have been included as side groups in PAA and crosslinked PAA. After 1 day of incubation with MnP, modified PA decrease Mw (34-63\%), and modified cross-linked PAA reduced their insoluble fractions $(41 \%)$, while non-modified polymers did not display significant changes (Ito et al. 2005). Also, PAN and PAAm C-C backbone grafted with N-benzyl4-vinylpyridinium chloride (BVP) became more biodegradable. BVP adheres to bacterial cells and maintains their viability favoring grafted polymer biodegradation (Kawabata et al. 2006; Kawabata and Fuse 2006). PAN-co-BVP
Fig. 4 Proposed hypothetical catabolic reactions involved in biodegradation of $\operatorname{poly}(n$-alkyl methacrylates) (PnAMA).

Different isomeric structures, based on Kawai et al. (1994) and Iwahashi et al. (2003), can be generated during PnAMA polymerization (upper structures). For the biodegradation of the different PnAMA isomers, distinct enzymatic reactions have to occur. Esterases must first cleave the side groups bound by ester bonds to the polymer, releasing alkyl alcohols. After that, the molecule has to be activated for entrance to $\beta$-oxidation. However, for the tail-to-tail isomer, mutases must shift the methyl group, from the last quaternary carbon unit, to a linear conformation, which would allow the first $\beta$-oxidation cycle. During $\beta$-oxidation, 2 or 3 carbons would be eliminated, depending on the isomer, producing CoA derivatives. Further reactions by phosphate transferases and kinases will produce organic acids. The remaining PnAMA polymer will need new reactions by mutases or decarboxylases for additional $\beta$-oxidation cycles<smiles>[R]OC(=O)C(C)CCC(C)(C)C(=O)O[R6](=O)OC(=O)O</smiles>

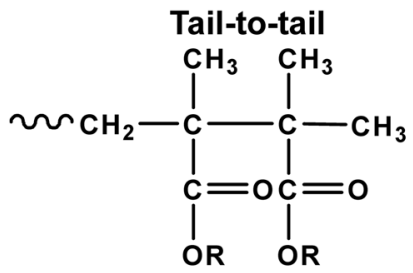<smiles>[R]OC(=O)C(C)CC(C)(CCO)C(=O)O[R]</smiles><smiles>CC(CCC(C)(C)C(=O)O)C(=O)O</smiles>

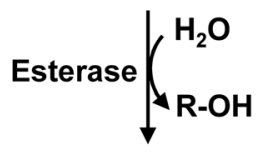

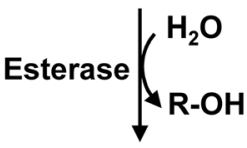

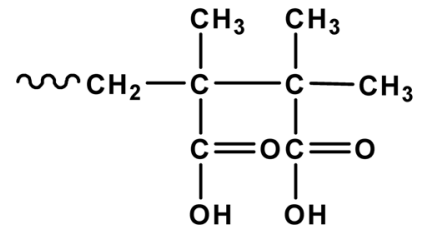<smiles>CCC(C)(CC(C)C)C(=O)O</smiles>

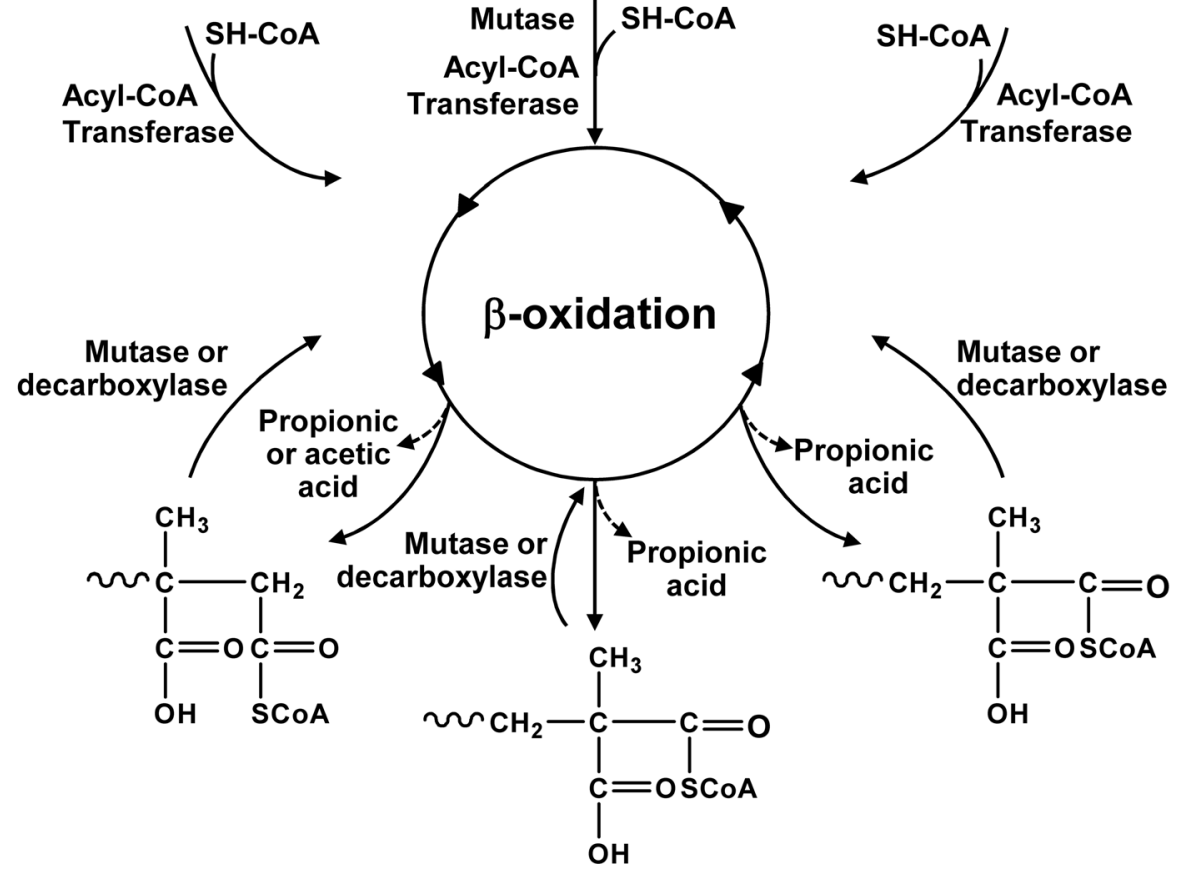


copolymers showed a $54-90 \%$ weight decrease after treated for 28 days with activated sludge in soil, while the nonmodified PAN weight remained constant (Kawabata et al. 2006). Similarly, PAAm-co-BVP exposed to an activated sludge for 7 days showed a TOC reduction up to $80 \%$ of its original value at the end of the treatment, while non-modified PAAm was unchanged (Kawabata and Fuse 2006). Also, the biodegradability of different types of AP, grafted with natural components such as storage or structural polysaccharides (cellulose, chitin, starch, or those contained in tamarind kernel powder), has been studied, showing more susceptibility to different enzymatic, bacteria, and fungi treatments than nongrafted AP (Saroja et al. 2000; Wang and Yang 2010; Mittal et al. 2013; Navarchian et al. 2013; Del Real et al. 2015; Saruchi et al. 2015). Although in most cases, AP grafting has been successful in achieving improved AP mineralization levels, there are cases where this strategy did not produce the expected results (Mai et al. 2004). Large size or high Mw of the AP chain might be the reason; thus, specific grafting strategies for each AP type and each biological system must be tested. However, this approach may not be as good as expected since it accelerates toxic monomers' release before complete mineralization is set.

Assisted bioremediation techniques that involve synergy between physical, chemical, and biological methods have been tested for AP waste treatment. Some of them include photodegradation by UV radiation (El-Mamouni et al. 2002), oxidation with the Fenton reagent (Zhang et al. 2019), or with zerovalent iron/EDTA/air (Lu and Wei 2011), as a pretreatment for aerobic or anaerobic biological process. In most cases, pretreatment improves AP solubilization by reducing $\mathrm{Mw}$; thus, hybrid technologies increase AP removal rates and enhance mineralization.

\section{Conclusions and perspectives}

The diversity of AP materials is equivalent to their extensive and increasing applications in multiple areas. Because AP materials had been considered not harmful for the environment and human health, no regulations for their use and waste disposal have been implemented in many countries. Nevertheless, the current information about the effect AP releases generate and the damages that can be foreseen by their accumulation in the environment, plus the toxicity of some of their components, indicates that regulations for controlling AP use and waste management should be established. Extensive and detailed analyses about the environmental fates AP could reach after their lifecycles would help develop better waste management strategies.

AP microbial biodegradation can be carried out on some types of polymers and to some extent. An AP biodegradability assessment, which defines the biodegradation rate a polymer is degraded, will depend on the polymer's structure, the microorganisms and the environment where the process is carried out, and the techniques used to quantitate AP degradation. The C-C backbone, the presence of side groups, quaternary carbons, and impurities of AP products significantly affect the biodegradability assessment, which is crucial in defining the magnitude of AP environmental impact. Therefore, unifying the use of techniques for measuring biodegradation would be beneficial for providing comparable data to define accurate biodegradation rates. Using isotopic C-labeled AP materials for quantifying transformation to $\mathrm{CO}_{2}$, biomass, or intermediate biodegradation products is the more objective approach. Moreover, performing long-time experiments is essential since the more quickly eliminated groups, measured in short-time experiments, generate overestimation of the degradation rates because the $\mathrm{C}-\mathrm{C}$ backbone cleavage, the most recalcitrant segment, is not quantified, providing with false expectations about how long an AP would last to be degraded.

Significant advances in the elucidation of AP biodegradative pathways have been reached, mainly supported by analytical techniques. Nevertheless, many aspects remain to be discovered. The characterization of enzymes accounting for the proposed reactions and the transport of the degradation products into the cells is still missing. Besides, nothing is known about the genes encoding these proteins and the genome organization, expression, and regulation of AP attacking microorganisms. The knowledge of genes encoding AP biodegradative enzymes will be a starting point for cloning genes for producing recombinant proteins, developing metabolic engineering strategies, and doing directed evolution research that will open a vast panorama for biotechnological advances. Furthermore, exploring the catalytic potential of environmental communities with AP degrading capacities by "omics" technologies is a promising strategy for designing tailor-made microbial consortia highly specialized for AP mineralization. Perhaps, future biotechnological-based products might include microorganisms or enzymes with a broad spectrum of activities that might efficiently degrade diverse AP types to prevent their accumulation in the environment.

Finally, we would like to stress that even though science and technology are working for searching solutions for plastic pollution by re-thinking the design of products and by developing holistic strategies to contribute to reducing the impact of polymers to the environment, the regulation for polymer use and waste management is in the governments and industries' hands.

Supplementary Information The online version contains supplementary material available at https://doi.org/10.1007/s00253-020-11073-1.

Acknowledgments IG and MB acknowledge Consejo Nacional de Ciencia y Tecnología for their PhD scholarships. The authors 
sincerely thank Dr. Alexander Steinbückel for the invitation to write this mini-review and the reviewer for the excellent suggestions for improving our manuscript.

Authors' contributions IGE and HLT conceived and designed this review's content, wrote most of the manuscript, analyzed all the subjects, contributed critical insights on acrylic polymers biodegradation, and designed the figures. MB wrote the "Acrylic polymers' chemistry, properties, and applications" section, advised on chemical nomenclature, compiled data in Table 1, and drew the chemical structures shown in the figures. All authors read and approved the manuscript.

Funding This work was supported by Programa de Apoyo a Proyectos de Investigación e Innovación Tecnológica, Dirección General de Asuntos del Personal Académico, Universidad Nacional Autónoma de México grant IN227620; Programa de Apoyo a la Investigacion y el Posgrado, Facultad de Química, Universidad Nacional Autónoma de México, grant 5000-9117; and Consejo Nacional de Ciencia y Tecnología. Ciencia de Frontera 2019 grant 101737.

\section{Compliance with ethical standards}

Competing interests The authors declare that they have no competing interests.

Ethical approval Not required.

\section{References}

Abo-Salem OM, Abd-Ellah MF, Ghonaim MM (2011) Hepatoprotective activity of quercetin against acrylonitrile-induced hepatotoxicity in rats. J Biochem Mol Toxicol 25:386-392. https://doi.org/10.1002/ jbt.20406

Adegbola TA, Agboola O, Fayomi OSI (2020) Review of polyacrylonitrile blends and application in manufacturing technology: recycling and environmental impact. Res Eng Des 7:100144. https://doi.org/ 10.1016/j.rineng.2020.100144

Aggour YA, Aziz MS (2000) Degradation of polyacrylonitrile by low energy ion beam and UV radiation. Polym Test 19:261-267. https:// doi.org/10.1016/S0142-9418(98)00087-7

Akkaya A, Ozseker EE (2019) Modification of polyacrylonitrile fabric for antibacterial application by tetracycline immobilization. Polym Test 78:105959. https://doi.org/10.1016/j.polymertesting.2019. 105959

Bai M, Wilske B, Buegger F, Esperschütz J, Bach M, Frede HG, Breuer L (2015) Relevance of nonfunctional linear polyacrylic acid for the biodegradation of superabsorbent polymer in soils. Environ Sci Pollut Res 22:5444-5452. https://doi.org/10.1007/s11356-0143772-0

Bao M, Chen Q, Li Y, Jiang G (2010) Biodegradation of partially hydrolyzed polyacrylamide by bacteria isolated from production water after polymer flooding in an oil field. J Hazard Mater 184:105110. https://doi.org/10.1016/j.jhazmat.2010.08.011

Bedade DK, Singhal RS (2018) Biodegradation of acrylamide by a novel isolate, Cupriavidus oxalaticus ICTDB921: identification and characterization of the acrylamidase produced. Bioresour Technol 261: 122-132. https://doi.org/10.1016/j.biortech.2018.04.012

Borak J, Fields C, Andrews LS, Pemberton MA (2011) Methyl methacrylate and respiratory sensitization: a critical review. Crit Rev Toxicol 41:230-268. https://doi.org/10.3109/10408444.2010. 532768
Cameron MD, Post ZD, Stahl JD, Haselbach J, Aust SD (2000) Cellobiose dehydrogenase-dependent biodegradation of polyacrylate polymers by Phanerochaete chrysosporium. Environ Sci Pollut Res 7:130-134. https://doi.org/10.1065/espr2000.04.022

Caulfield MJ, Qiao GG, Solomon DH (2002) Some aspects of the properties and degradation of polyacrylamides. Chem Rev 102:30673083. https://doi.org/10.1021/cr010439p

Chand D, Kumar H, Sankhian UD, Kumar D, Vitzthum F, Chand T (2004) Treatment of simulated wastewater containing toxic amides by immobilized Rhodococcus rhodochrous NHB-2 using a highly compact 5-stage plug flow reactor. World J Microbiol Biotechnol 20:679-686. https://doi.org/10.1007/s11274-004-2158-8

Chang JS, Abu-Orf M, Dentel SK (2005) Alkylamine odors from degradation of flocculant polymers in sludges. Water Res 39:3369-3375. https://doi.org/10.1016/j.watres.2005.05.047

Chiellini E, Corti A, D'Antone S, Solaro R (2003) Biodegradation of poly (vinyl alcohol) based materials. Prog Polym Sci 28:963-1014. https://doi.org/10.1016/S0079-6700(02)00149-1

Cook BD, Bloom PR, Halbach TR (1997) Fate of a polyacrylate polymer during composting of simulated municipal solid waste. J Environ Qual 26:618-625. https://doi.org/10.2134/jeq1997. $00472425002600030005 x$

Dai X, Luo F, Yi J, He Q, Dong B (2014) Biodegradation of polyacrylamide by anaerobic digestion under mesophilic condition and its performance in actual dewatered sludge system. Bioresour Technol 153:55-61. https://doi.org/10.1016/j.biortech.2013.11.007

Dai X, Luo F, Zhang D, Dai L, Chen Y, Dong B (2015) Waste-activated sludge fermentation for polyacrylamide biodegradation improved by anaerobic hydrolysis and key microorganisms involved in biological polyacrylamide removal. Sci Rep 5:1-13. https://doi.org/10. 1038/srep11675

De Matos O (2019) The ECETOC conceptual framework for polymer risk assessment (CF4Polymers). Technical Report No. ECETOC AISBL, European Centre for Ecotoxicology and Toxicology of Chemicals, Brussels, pp 133-131

Del Real A, Wallander D, Maciel A, Cedillo G, Loza H (2015) Graft copolymerization of ethyl acrylate onto tamarind kernel powder, and evaluation of its biodegradability. Carbohydr Polym 117:11-18. https://doi.org/10.1016/j.carbpol.2014.09.044

DeLeo PC, Summers H, Stanton K, Lam MW (2020) Environmental risk assessment of polycarboxylate polymers used in cleaning products in the United States. Chemosphere 258:127242. https://doi.org/10. 1016/j.chemosphere.2020.127242

Dell'Ambrogio G, Wong JWY, Ferrari BJD (2019) Ecotoxicological effects of polyacrylate, acrylic acid, polyacrylamide and acrylamide on soil and water organisms. Swiss Centre for Applied Ecotoxicology, Lausanne

El-Mamouni R, Frigon J, Hawari J, Marroni D, Guiot SR (2002) Combining photolysis and bioprocesses for mineralization of high molecular weight polyacrylamides. Biodegradation 13:221-227. https://doi.org/10.1023/A:1021272519714

Esmizadeh E, Khalili S, Vahidifar A, Naderi G, Dubois C (2019) Waste polymethyl methacrylate (PMMA): recycling and high-yield monomer recovery. In: Handbook of ecomaterials. Springer Nature, Switzerland. https://doi.org/10.1007/978-3-319-68255-6_164

EURAR (2004) European Union Risk Assessment Report AN. https:// echa.europa.eu/documents/10162/22bf49d3-e951-44b8-a45a6973d3dc62f6. Accessed 23 October 2020.

Fater (2020) Our challenge is to turn the use of baby diapers, hygienic pads and incontinence products into an advantage also for the environment. https://fatergroup.com/en/news/recycling-project. Accessed 23 October 2020

Fischer-Colbrie G, Herrmann M, Heumann S, Puolakka A, Wirth A, Cavaco-Paulo A, Guebitz GM (2006) Surface modification of polyacrylonitrile with nitrile hydratase and amidase from Agrobacterium 
tumefaciens. Biocatal Biotransform 24:419-425. https://oi.org/10. 1080/10242420601033977

Freeman MB, Bender TM (1993) An environmental fate and safety assessment for a low molecular weight polyacrylate detergent additive. Environ Technol 14:101-112. https://doi.org/10.1080/ 09593339309385269

Freeman MB, Paik YH, Swift G, Wilczynski R, Wolk SK, Yocom KM (1996) Biodegradability of polycarboxylates: structure-activity studies. ACS Symposium Series. American Chemical Society, Washington, DC, pp 118-136

Gaytán I, Sánchez-Reyes A, Burelo M, Vargas-Suárez M, Liachko I, Press M, Sullivan S, Cruz-Gómez MJ, Loza-Tavera H (2020) Degradation of recalcitrant polyurethane and xenobiotic additives by a selected landfill microbial community and its biodegradative potential revealed by proximity ligation-based metagenomic analysis. Front Microbiol 10:2986. https://doi.org/10.3389/fmicb.2019. 02986

Gitalis R, Zhou L, Marashdeh MQ, Sun C, Glogauer M, Finer Y (2019) Human neutrophils degrade methacrylate resin composites and tooth dentin. Acta Biomater 88:325-331. https://doi.org/10.1016/j. actbio.2019.02.033

Gong JS, Lu ZM, Li H, Shi JS, Zhou ZM, Xu ZH (2012) Nitrilases in nitrile biocatalysis: recent progress and forthcoming research. Microb Cell Factories 11:1-18. https://doi.org/10.1186/1475-2859$11-142$

Hayashi T, Mukouyama M, Sakano K, Tani Y (1993) Degradation of a sodium acrylate oligomer by an Arthrobacter sp. Appl Environ Microbiol 59:1555-1559. https://doi.org/10.1128/aem.59.5.15551559.1993

Hayashi T, Nishimura H, Sakano K, Tani Y (1994) Microbial degradation of poly(sodium acrylate). Biosci Biotechnol Biochem 58:444-446. https://doi.org/10.1271/bbb.58.444

Hennecke D, Bauer A, Herrchen M, Wischerhoff E, Gores F (2018) Cationic polyacrylamide copolymers (PAMs): environmental half life determination in sludge-treated soil. Environ Sci Eur 30(16):113. https://doi.org/10.1186/s12302-018-0143-3

Huang B, Sadeghinejad L, Adebayo OIA, Ma D, Xiao Y, Siqueira WL, Cvitkovitch DG, Finer Y (2018) Gene expression and protein synthesis of esterase from Streptococcus mutans are affected by biodegradation by-product from methacrylate resin composites and adhesives. Acta Biomater 81:158-168. https://doi.org/10.1016/j.actbio. 2018.09.050

Ito S, Okada Y, Hirai H, Nishida T (2005) Degradation of poly(acrylic acid)s with phenolic side-chains by manganese peroxidase from white rot fungi. J Polym Environ 13:357-363. https://doi.org/10. 1007/s10924-005-5530-3

Iwahashi M, Katsuragi T, Tani Y, Tsutsumi K, Kakiuchi K (2003) Mechanism for degradation of poly(sodium acrylate) by bacterial consortium no. L7-98. J Biosci Bioeng 95:483-487. https://doi. org $/ 10.1263 / \mathrm{jbb} .95 .483$

Jebasingh SEJ, Lakshmikandan M, Rajesh RP, Raja P (2013) Biodegradation of acrylamide and purification of acrylamidase from newly isolated bacterium Moraxella osloensis MSU11. Int Biodeterior Biodegrad 85:120-125. https://doi.org/10.1016/j.ibiod. 2013.06.012

Joshi SJ, Abed RMM (2017) Biodegradation of polyacrylamide and its derivatives. Environ Process 4:463-476. https://doi.org/10.1007/ s40710-017-0224-0

Kawabata N, Fuse T (2006) Coagulation and sedimentation of bacteria using a highly biodegradable polymeric coagulant. J Appl Polym Sci 100:1618-1623. https://doi.org/10.1002/app.23669

Kawabata N, Ohashi K, Nishiyama T (2006) Releasing polyacrylonitrile from poor biodegradability by insertion of a highly biodegradable chemical structure into the main chain. J Appl Polym Sci 99:852857. https://doi.org/10.1002/app.22591
Kawai F (1993) Bacterial degradation of acrylic oligomers and polymers. Appl Microbiol Biotechnol 39:382-385. https://doi.org/10.1007/ BF00192097

Kawai F, Igarashi K, Kasuya F, Fukui M (1994) Proposed mechanism for bacterial metabolism of polyacrylate. J Environ Polym Degrad 2: 59-65. https://doi.org/10.1007/BF02074774

Kay-Shoemake JL, Watwood ME, Lentz RD, Sojka RE (1998a) Polyacrylamide as an organic nitrogen source for soil microorganisms with potential effects on inorganic soil nitrogen in agricultural soil. Soil Biol Biochem 30:1045-1052. https://doi.org/10.1016/ S0038-0717(97)00250-2

Kay-Shoemake JL, Watwood ME, Sojka RE, Lentz RD (1998b) Polyacrylamide as a substrate for microbial amidase in culture and soil. Soil Biol Biochem 30:1647-1654. https://doi.org/10.1016/ S0038-0717(97)00251-4

Kikuchi Y, Hirao M, Ookubo T, Sasaki A (2014) Design of recycling system for poly(methyl methacrylate) (PMMA). Part 1: recycling scenario analysis. Int J Life Cycle Assess 19:120-129. https://doi. org/10.1007/s11367-013-0624-y

Kolvenbach BA, Helbling DE, Kohler HE, Corvini PF (2014) Emerging chemicals and the evolution of biodegradation capacities and pathways in bacteria. Curr Opin Biotechnol 27:8-14. https://doi.org/10. 1016/j.copbio.2013.08.017

Larson RJ, Bookland EA, Williams RT, Yocom KM, Saucy DA, Freeman MB, Swift G (1997) Biodegradation of acrylic acid polymers and oligomers by mixed microbial communities in activated sludge. J Environ Polym Degrad 5:41-48. https://doi.org/10.1007/ BF02763567

Lu M, Wei X (2011) Treatment of oilfield wastewater containing polymer by the batch activated sludge reactor combined with a zerovalent iron/EDTA/air system. Bioresour Technol 102:2555-2562. https:// doi.org/10.1016/j.biortech.2010.11.103

Mahalik JP, Madras G (2005) Effect of the alkyl group substituents on the thermal and enzymatic degradation of poly(n-alkyl acrylates). Ind Eng Chem Res 44:4171-4177. https://doi.org/10.1021/ie0500164

Mai C, Schormann W, Majcherczyk A, Hüttermann A (2004) Degradation of acrylic copolymers by white-rot fungi. Appl Microbiol Biotechnol 65:479-487. https://doi.org/10.1007/s00253004-1668-5

Maksimova YG, Vasil'ev DM, Zorina AS, Ovechkina GV, Maksimov AY (2018) Acrylamide and acrylic acid biodegradation by Alcaligenes faecalis 2 planktonic cells and biofilms. Appl Biochem Microbiol 54:173-178. https://doi.org/10.1134/ s0003683818020084

Matamá T, Carneiro F, Caparrós C, Gübitz GM, Cavaco-Paulo A (2007) Using a nitrilase for the surface modification of acrylic fibres. Biotechnol J 2:353-360. https://doi.org/10.1002/biot.200600068

McKeen LW (2012) Styrenic plastics. In: Permeability properties of plastics and elastomers, Plastics Design Library (Third Edition). William Andrew Publishing, pp 77-88. https://doi.org/10.1016/B978-14377-3469-0.10005-0

Mittal H, Fosso-Kankeu E, Mishra SB, Mishra AK (2013) Biosorption potential of Gum ghatti-g-poly(acrylic acid) and susceptibility to biodegradation by $B$. subtilis. Int J Biol Macromol 62:370-378. https://doi.org/10.1016/j.ijbiomac.2013.09.023

Morro A, Catalina F, Corrales T, Pablos JL, Marin I, Abrusci C (2016) New blends of ethylene-butyl acrylate copolymers with thermoplastic starch. Characterization and bacterial biodegradation. Carbohydr Polym 149:68-76. https://doi.org/10.1016/j.carbpol.2016.04.075

Mosley AP (2017) Acrylic plastics. Brydson's plastics materials, eighth edition. Elsevier Ltd, pp 441-456. https://doi.org/10.1016/B978-0323-35824-8.00016-5

Müller D, Gabriel J (1999) Bacterial degradation of the herbicide bromoxynil by Agrobacterium radiobacter in biofilm. Folia Microbiol 44:377-379. https://doi.org/10.1007/BF02903708 
Narihiro T, Nobu MK, Tamaki H, Kamagata Y, Sekiguchi Y, Liu WT (2016) Comparative genomics of syntrophic branched-chain fatty acid degrading bacteria. Microbes Environ 31:288-292. https:// doi.org/10.1264/jsme2.ME16057

Navarchian AH, Sharafi A, Kermanshahi RK (2013) Biodegradation study of starch-graft-acrylonitrile copolymer. J Polym Environ 21: 233-244. https://doi.org/10.1007/s10924-012-0518-2

Nuss P, Gardner KH (2013) Attributional life cycle assessment (ALCA) of polyitaconic acid production from northeast US softwood biomass. Int J Life Cycle Assess 18:603-612. https://doi.org/10.1007/ s11367-012-0511-y

Nyyssölä A, Ahlgren J (2019) Microbial degradation of polyacrylamide and the deamination product polyacrylate. Int Biodeterior Biodegrad 139:24-33. https://doi.org/10.1016/j.ibiod.2019.02.005

O'Leary KA, Paul DR (2006) Physical properties of poly(n-alkyl acrylate) copolymers. Part 1. Crystalline/crystalline combinations. Polymer 47:1226-1244. https://doi.org/10.1016/j.polymer.2005. 12.005

Oksińska MP, Magnucka EG, Lejcuś K, Jakubiak-Marcinkowska A, Ronka S, Trochimczuk AW, Pietr SJ (2019) Colonization and biodegradation of the cross-linked potassium polyacrylate component of water absorbing geocomposite by soil microorganisms. Appl Soil Ecol 133:114-123. https://doi.org/10.1016/j.apsoil.2018.09.014

P2L (2019) Innovative and environmentally friendly acrylic (PMMApolymethyl methacrylate) recycling technology. http://www. plant2life.com. Accessed 23 October 2020

Pemberton MA, Lohmann BS (2014) Risk assessment of residual monomer migrating from acrylic polymers and causing allergic contact dermatitis during normal handling and use. Regul Toxicol Pharmacol 69:467-475. https://doi.org/10.1016/j.yrtph.2014.05. 013

PMMA (2018) PMMA/acrylic sustainable solutions. https://www.pmmaonline.eu/sustainability/. Accessed 23 October 2020

Probian C, Wulfin A, Harder J (2003) Anaerobic mineralization of quaternary carbon atoms: isolation of denitrifying bacteria on pivalic acid (2,2-dimethylpropionic acid). Appl Environ Microbiol 69: 1866-1870. https://doi.org/10.1128/AEM.69.3.1866-1870.2003

Rustamov IR, Dyatlov VA, Grebeneva TA, Dyatlov AV, Zaitsev VV, Maleev VI (2014) Polycyanoacrylate porous material for bone tissue substitution. J Mater Chem B 2:4310-4317. https://doi.org/10.1039/ c4tb00554f

Sabatini V, Cattò C, Cappelletti G, Cappitelli F, Antenucci S, Farina H, Ortenzi MA, Camazzola S, Di Silvestro G (2018) Protective features, durability and biodegradation study of acrylic and methacrylic fluorinated polymer coatings for marble protection. Prog Org Coat 114:47-57. https://doi.org/10.1016/j.porgcoat.2017.10.003

Šajn N (2019) Environmental impact of the textile and clothing industry. EPRS|European Parliamentary Research Service, European Union

Sang G, Pi Y, Bao M, Li Y, Lu J (2015) Biodegradation for hydrolyzed polyacrylamide in the anaerobic baffled reactor combined aeration tank. Ecol Eng 84:121-127. https://doi.org/10.1016/j.ecoleng.2015. 07.028

Saroja N, Shamala TR, Tharanathan RN (2000) Biodegradation of starchg-polyacrylonitrile, a packaging material, by Bacillus cereus. Process Biochem 36:119-125. https://doi.org/10.1016/S00329592(00)00190-4

Saruchi, Kaith BS, Jindal R, Kumar V (2015) Biodegradation of Gum tragacanth acrylic acid based hydrogel and its impact on soil fertility. Polym Degrad Stab 115:24-31. https://doi.org/10.1016/j. polymdegradstab.2015.02.009

Sein TT, Spurio R, Cecchini C, Cresci A (2009) Screening for microbial strains degrading glass fiber acrylic composite filters. Int Biodeterior Biodegrad 63:901-905. https://doi.org/10.1016/j.ibiod.2009.06.002

Serrano-Aroca Á (2017) Latest improvements of acrylic-based polymer properties for biomedical applications. Acrylic polym healthcare.
IntechOpen, Rijeka, pp 75-98. https://doi.org/10.5772/intechopen. 68996

Seybold CD (1994) Polyacrylamide review: Soil conditioning and environmental fate. Commun Soil Sci Plant Anal 25:2171-2185. https:// doi.org/10.1080/00103629409369180

Sharma M, Nand N (2009) Amidases: versatile enzymes in nature. Rev Environ Sci Biotechnol 8:343-366. https://doi.org/10.1007/s11157$009-9175-\mathrm{x}$

Shimi (2020) Acrylic Plastic Waste Cracking Unit, Shimi Research Center. http://shimiresearch.in/Acrylic-Recycling.php. Accessed 23 October 2020

Shukla NB, Daraboina N, Madras G (2009) Oxidative and photooxidative degradation of poly(acrylic acid). Polym Degrad Stab 94:1238 1244. https://doi.org/10.1016/j.polymdegradstab.2009.04.020

Silman NJ, Carver MA, Jones CW (1991) Directed evolution of amidase in Methylophilus methylotrophus: purification and properties of amidases from wild-type and mutant strains. J Gen Microbiol 137:169178. https://doi.org/10.1099/00221287-137-1-169

Solano-Serena F, Marchal R, Heiss S, Vandecasteele JP (2004) Degradation of isooctane by Mycobacterium austroafricanum IFP 2173: growth and catabolic pathway. J Appl Microbiol 97:629-639. https://doi.org/10.1111/j.1365-2672.2004.02344.x

Song T, Li S, Lu Y, Yan D, Sun P, Bao M, Li Y (2019) Biodegradation of hydrolyzed polyacrylamide by a Bacillus megaterium strain SZK-5: functional enzymes and antioxidant defense mechanism. Chemosphere 231:184-193. https://doi.org/10.1016/j. chemosphere.2019.05.143

Stahl JD, Cameron MD, Haselbach J, Aust SD (2000) Biodegradation of superabsorbent polymers in soil. Environ Sci Pollut Res 7:83-88. https://doi.org/10.1065/espr199912.014

Sutherland GRJ, Haselbach J, Aust SD (1997) Biodegradation of crosslinked acrylic polymers by a white-rot fungus. Environ Sci Pollut Res 4:16-20. https://doi.org/10.1007/BF02986258

Swick RW (1962) Propionic acid metabolism: mechanism of the methylmalonyl isomerase reaction and the reduction of acrylyl coenzyme a to propionyl coenzyme a in propionibacteria. Proc Natl Acad Sci U S A 48(2):288-293. https://doi.org/10.1073/pnas.48.2. 288

Tauber MM, Cavaco-Paulo A, Robra KH, Gübitz GM (2000) Nitrile hydratase and amidase from Rhodococcus rhodochrous hydrolyze acrylic fibers and granular polyacrylonitriles. Appl Environ Microbiol 66:1634-1638. https://doi.org/10.1128/AEM.66.4.16341638.2000

Vargas-Suárez M, Fernández-Cruz V, Loza-Tavera H (2019) Biodegradation of polyacrylic and polyester polyurethane coatings by enriched microbial communities. Appl Microbiol Biotechnol 103:3225-3236. https://doi.org/10.1007/s00253-019-09660-y

Wang Y, Yang JF (2010) Physical properties and biodegradation of acrylic acid grafted poly ( $\varepsilon$-caprolactone)/chitosan blends. J Polym Res 17:221-232. https://doi.org/10.1007/s10965-009-9308-5

Wen Q, Chen Z, Zhao Y, Zhang H, Feng Y (2010) Biodegradation of polyacrylamide by bacteria isolated from activated sludge and oilcontaminated soil. J Hazard Mater 175:955-959. https://doi.org/10. 1016/j.jhazmat.2009.10.102

Wilske B, Bai M, Lindenstruth B, Bach M, Rezaie Z, Frede HG, Breuer L (2014) Biodegradability of a polyacrylate superabsorbent in agricultural soil. Environ Sci Pollut Res 21:9453-9460. https://doi.org/10. 1007/s11356-013-2103-1

Wiśniewska M (2018) Polyacrylamide (PAM). In: PM V, AO S (eds) High performance polymers and their nanocomposites. Wiley, New Jersey, pp 105-131. https://doi.org/10.1002/9781119363910.ch4

Xiong B, Loss RD, Shields D, Pawlik T, Hochreiter R, Zydney AL, Kumar M (2018) Polyacrylamide degradation and its implications in environmental systems. npj Clean Water 1(17):1-9. https://doi. org/10.1038/s41545-018-0016-8 
Yamada H, Kobayashi M (1996) Nitrile hydratase and its application to industrial production of acrylamide. Biosci Biotechnol Biochem 60: 1391-1400. https://doi.org/10.1271/bbb.60.1391

Yongrui P, Zheng Z, Bao M, Li Y, Zhou Y, Sang G (2015) Treatment of partially hydrolyzed polyacrylamide wastewater by combined fenton oxidation and anaerobic biological processes. Chem Eng J 273:1-6. https://doi.org/10.1016/j.cej.2015.01.034

Yu F, Fu R, Xie Y, Chen W (2015) Isolation and characterization of polyacrylamide-degrading bacteria from dewatered sludge. Int $\mathrm{J}$ Environ Res Public Health 12:4214-4230. https://doi.org/10.3390/ ijerph120404214

Zhang L, Su F, Wang N, Liu S, Yang M, Wang Y, Huo D, Zhao T (2019) Biodegradability enhancement of hydrolyzed polyacrylamide wastewater by a combined Fenton-SBR treatment process.
Bioresour Technol 278:99-107. https://doi.org/10.1016/j.biortech. 2019.01.074

Zhao L, Song T, Han D, Bao M, Lu J (2019) Hydrolyzed polyacrylamide biotransformation in an up-flow anaerobic sludge blanket reactor system: key enzymes, functional microorganisms, and biodegradation mechanisms. Bioprocess Biosyst Eng 42:941-951. https://doi. org/10.1007/s00449-019-02094-w

Zohuriaan-Mehr MJ, Kabiri K (2008) Superabsorbent polymer materials: a review. Iran Polym J 17(6):451-477

Publisher's note Springer Nature remains neutral with regard to jurisdictional claims in published maps and institutional affiliations. 